\title{
First case of laboratory-confirmed Zika virus infection imported into Europe, November 2013
}

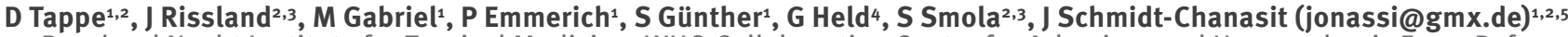

1. Bernhard Nocht Institute for Tropical Medicine, WHO Collaborating Centre for Arbovirus and Haemorrhagic Fever Reference and Research, Hamburg, Germany

2. These authors contributed equally to this work

3. Institute of Virology, Saarland University Medical Center, Homburg/Saar, Germany

4. Internal Medicine I, Saarland University Medical Center, Homburg/Saar, Germany

5. German Centre for Infection Research (DZIF), partner site Hamburg-Luebeck-Borstel, Hamburg, Germany

Citation style for this article:

Tappe D, Rissland J, Gabriel M, Emmerich P, Günther S, Held G, Smola S, Schmidt-Chanasit J. First case of laboratory-confirmed Zika virus infection imported into Europe, November 2013. Euro Surveill. 2014;19(4):pii=20685. Available online: http://www.eurosurveillance.org/ViewArticle.aspx?Articleld=20685

Article submitted on 27 January 2014 / published on 30 January 2014

In November 2013, an acute Zika virus (ZIKV) infection was diagnosed in a German traveller returning from Thailand. The patient reported a clinical picture resembling dengue fever. Serological investigations revealed anti-ZIKV-IgM and -IgG, as well as ZIKVspecific neutralising antibodies in the patient's blood. In Europe, viraemic travellers may become a source of local transmission of ZIKV, because Aedes albopictus (Skuse) and Ae. aegypti (Linnaeus) are invasive mosquitoes and competent vectors for ZIKV.

We report the clinical and laboratory findings of a Zika virus (ZIKV) infection imported into Europe by a German traveller from Thailand, in winter of 2013.

\section{Case description}

A previously healthy German traveller in his early 50 s was seen at a tertiary hospital, Germany, on 22 November 2013, after returning from a vacation in Thailand. During the patient's three-week round trip (in early November) which included visits to Phuket, Krabi, Ko Jum, and Ko Lanta, he developed joint pain and swelling of his left ankle and foot on 12 days after entering the country. Pain and swelling was followed by a maculopapular rash on his back and chest that later spread to the face, arms, and legs over a period of four days before fading. Concomitantly, the patient suffered from malaise, fever (self-reported), and chills. Fever and shivering were treated by self-medication with non-steroidal anti-inflammatory drugs and only lasted for one day. The patient had noted several mosquito bites previously, despite using insect repellents regularly. He had sought pre-travel advice and his travel partner did not have any symptoms and also did not develop any.

Upon return to Germany, the patient was asymptomatic except for the subjective complaint of ongoing exhaustion. Physical examination was normal and no particular treatment was initiated. Laboratory parameters 10 days after disease onset revealed a slightly increased
C-reactive protein level $(5.9 \mathrm{mg} / \mathrm{L}$; normal value $<5.0)$, a normal leucocyte count of $8,200 \mathrm{~g} / \mu \mathrm{L}$ ( $45 \%$ lymphocytes, 5\% monocytes, and a mildly decreased relative neutrophil count of $47 \%$ (normal range: $50-75 \%$ )). Platelet count was normal with $238,000 \mathrm{~g} / \mu \mathrm{L}$. Lactate dehydrogenase levels were elevated (311 U/L; normal <262 U/L), with an increased plasma fibrinogen concentration (422 mg/dL; normal range: $180-400 \mathrm{mg} / \mathrm{dL}$ ) and serum ferritin concentration $(486 \mathrm{ng} / \mathrm{mL}$; normal range: 30-400). Serum electrophoresis, clotting tests, kidney and liver function tests were normal except for an increased gamma-glutamyltransferase activity of 81 $\mathrm{U} / \mathrm{L}$ (normal $<60 \mathrm{U} / \mathrm{L}$ ).

A serum sample from the same day (10 days after symptom onset) showed a positive result for anti-dengue virus (DENV)-IgM in both the indirect immunofluorescence assay (IIFA), according to [1-3]) and rapid test (SD BIOLINE Dengue Duo NS1 Ag + Ab Combo). However, anti-DENV-IgG was not detected in either test. Testing for DENV nonstructural protein-1 (NS1) antigen (tested by enzyme-linked immunosorbent assay (ELISA): BioRad Platelia Dengue NS1 Ag) and rapid test (SD BIOLINE Dengue Duo NS1 Ag + Ab Combo) were also negative. The detection of isolated anti-DENV-IgM prompted us to investigate a probable flavivirus etiology other than DENV of the patient's illness. Serological tests for Japanese encephalitis virus (JEV), West Nile virus (WNV), yellow fever virus (YFV), tick-borne encephalitis virus (TBEV), and ZIKV were performed according to [1-3] and the IIFAs showed only positive results for anti-ZIKV-IgM and -IgG antibodies (Table), demonstrating an acute or recent ZIKV-infection of the patient. Serological tests for chikungunya virus (CHIKV) were negative (Table).

ZIKV-specific real-time reverse transcription-polymerase chain reaction (RT-PCR) (in-house) with primers ZIKAf (5'-TGGAGATGAGTACATGTATG-3'), ZIKAr (5'-GGTAGATGTTGTCAAGAAG-3'), probe - labeled with 6- carboxyfluorescein (FAM) and black hole quencher 1 


\begin{tabular}{|c|c|c|c|}
\hline \multirow{2}{*}{ Antibody or antigen tested } & \multicolumn{3}{|c|}{ Serum samples taken after symptom onset (days) } \\
\hline & 10 & 31 & 67 \\
\hline Anti-ZIKV-IgGa & $1: 5,120$ & $1: 2,560$ & $1: 2,560$ \\
\hline Anti-DENV-IgGa & $\langle 1: 20$ & $1: 80$ & $1: 160$ \\
\hline Anti-DENV-IgMa & $1: 40$ & $\langle 1: 20$ & $\langle 1: 20$ \\
\hline DENV NS $1^{\mathrm{b}}$ & $\begin{array}{c}\text { Negative } \\
\text { (o.1 arbitrary units) }\end{array}$ & $\begin{array}{c}\text { Negative } \\
\text { (0.2 arbitrary units) }\end{array}$ & $\begin{array}{c}\text { Negative } \\
\text { (o.1 arbitrary units) }\end{array}$ \\
\hline Anti-JEV-IgGa & $\langle 1: 20$ & $1: 40$ & $1: 20$ \\
\hline Anti-JEV-IgMa & $\langle 1: 20$ & $\langle 1: 20$ & $\langle 1: 20$ \\
\hline Anti-WNV-IgGa & $\langle 1: 20$ & $1: 20$ & $1: 80$ \\
\hline Anti-WNV-IgMa & $\langle 1: 20$ & $\langle 1: 20$ & $\langle 1: 20$ \\
\hline Anti-YFV-IgG ${ }^{a}$ & $\langle 1: 20$ & $\langle 1: 20$ & $1: 20$ \\
\hline Anti-CHIKV-IgGa & $\langle 1: 20$ & $\langle 1: 20$ & $\langle 1: 20$ \\
\hline Anti-CHIKV-IgMa & $\langle 1: 20$ & $\langle 1: 20$ & $\langle 1: 20$ \\
\hline
\end{tabular}

CHIKV: chikungunya virus; DENV: dengue virus; JEV: Japanese encephalitis virus; NS1: nonstructural protein-1; WNV: West Nile virus; YFV: yellow fever virus; ZIKV: Zika virus.

Indirect immunofluorescence assay (IIFA) titres «1:20 for serum were considered negative [1-3].

b SD BIOLINE Dengue Duo NS1 Ag + Ab Combo and Bio-Rad Platelia Dengue NS1 Ag.

(BHQ-1) - ZIKAp (5'-FAM-CTGATGAAGGCCATGCACACTGBHQ1-3) was negative on serum. Generic flavivirus real-time RT-PCR [4] was negative as well on serum. A significant 5 -fold anti-ZIKV-IgM titre decrease in the IIFA was demonstrated in the third serum sample collected 67 days after disease onset (Table). The presence of ZIKV-specific neutralising antibodies in the third serum sample was confirmed by a virus neutralisation assay. No laboratory investigation was conducted with the travel partner.

\section{Background}

ZIKV is a mosquito-borne RNA virus of the Flaviviridae family causing a dengue fever -like syndrome in humans. The virus was first isolated in 1947 from a febrile sentinel rhesus monkey in the Zika Forest of Uganda [5]. ZIKV virus is thought to be maintained in a sylvatic cycle involving non-human primates and several Aedes species (Ae. africanus, Ae. aegypti, and others) as mosquito vectors [6-8]. Human infection is acquired after an infective mosquito bite in endemic countries. However, the possibility of a secondary sexual transmission has been reported recently [9]. The virus is endemic in Africa and south-east Asia [8], and phylogenetic analysis suggested that African and Asian strains emerged as two distinct lineages [10-11]. ZIKV has caused an outbreak involving 49 confirmed and 59 probable cases on Yap Island, Federated States of Micronesia, in 2007 [12]. This outbreak highlighted the potential of the virus as an emerging pathogen [9], and epidemiological and phylogenetic studies provided evidence that the outbreak strain has been introduced from south-east Asia [10].

The most common signs and symptoms of ZIKV infection are rash, fever, arthralgia, myalgia, headache, and conjunctivitis. The rash is most often maculopapular. Occasionally, oedema, sore throat, cough, vomiting, and loose bowels are reported [11-13]. ZIKV infection can easily be confused with dengue and might be misdiagnosed during local dengue outbreaks [8]. ZIKV-associated illness may thus be underreported or misdiagnosed [9].

In contrast to acute dengue cases, our patient neither showed elevated aspartate amino transferase (AST) or alanine amino transferase (ALT) levels, nor thrombocytopenia. It is unclear whether these test results may help in differentiating ZIKV from dengue cases, as information about laboratory data during ZIKV infection is very scarce. An Australian case [11] did not show thrombocytopenia or elevated liver function tests either. It was reported recently that a low platelet count is a key variable distinguishing between dengue versus chikungunya [14], the latter being another mosquito-borne virus infection with similar clinical presentation and geographical distribution. Chikungunya is thus also an important differential diagnosis for ZIKV disease and future studies might address this issue for ZIKV. 
Despite the virus endemicity in many geographical areas and its potential to cause outbreaks, imported cases to non-endemic areas are rarely reported. In 2013, one imported case from Indonesia to Australia and one imported case from Thailand to Canada were diagnosed in travellers $[11,15]$. Also in the Australian and Canadian cases, anti-DENV-IgM was positive and DENV NS1 antigen testing was negative. In both cases, ZIKV infection was diagnosed after sequencing of a positive generic flavivirus RT-PCR amplicon. Four further cases of imported ZIKV to temperate regions have been reported in American scientists who had returned from Senegal and in Japanese travellers who returned from French Polynesia, where a ZIKV outbreak is currently ongoing $[16,17]$. A secondary infection in the wife of one of the American patients was assumed to be due to sexual contact [9]. The ZIKV outbreak in French Polynesia so far comprises more than 361 laboratoryconfirmed cases [18]. The first indigenous infection in New Caledonia was recently reported suggesting the spread of ZIKV, as 26 imported cases of ZIKV infection from French Polynesia have been observed in this territory [19].

\section{Conclusions}

This report constitutes, to the best of our knowledge, the first laboratory-confirmed case of a ZIKV infection imported into Europe. The case highlights that unusual DENV serology results might be caused by a flavivirus different than DENV despite a similar clinical picture. A serological study after the Yap outbreak indicated that ZIKV-infected patients can be positive in anti-DENVIgM assays [20], as also experienced in our case. This cross-reaction in the Yap outbreak was seen especially if ZIKV was a secondary flavivirus infection. These findings underscore the importance of a careful diagnostic investigation in travellers suspected with dengue, and the well-known serological cross-reactions in the flavivirus group. Thus, the rate at which seemingly imported dengue cases among travellers from endemic areas in the recent years were actually ZIKV infections remains a question.

In all published cases of imported ZIKV infections, in outbreak and sporadic endemic cases, the symptoms were dengue-like. Clinicians, virologists, and public health authorities should thus be aware of this emerging flavivirus infection. As the local transmission of DENV by previously introduced competent vectors in non-endemic countries has recently been reported from Croatia, France and Madeira [2,21,22], there might be the risk of a similar establishment in Europe of ZIKV, after import by viraemic travellers, in particular in areas where ZIKV competent vectors Ae. albopictus and Ae.aegypti are present.

\section{Acknowledgments}

We would like to thank Insa Bonow, Corinna Thomé and Birgit Hüsing for technical assistance.
Conflict of interest

None declared.

Authors' contributions

Wrote the manuscript: JSC, SG, DT, JR, SS, GH; performed laboratory or epidemiological investigations: JSC, PE, MG, JR, GH, DT; performed data analysis: JSC, PE, JR, GH.

\section{References}

1. Tappe D, Schmidt-Chanasit J, Ries A, Ziegler U, Müller A, Stich A. Ross River virus infection in a traveller returning from northern Australia. Med Microbiol Immunol. 2009;198(4):2713. http://dx.doi.org/10.1007/s00430-009-0122-9

2. Schmidt-Chanasit J, Haditsch $M$, Schöneberg I, Günther S, Stark K, Frank C. Dengue virus infection in a traveller returning from Croatia to Germany. Euro Surveill. 2010;15(40):pii: 19677. Available from: http://www.eurosurveillance.org/ViewArticle. aspx?Articleld $=19677$

3. Schmidt-Chanasit J, Emmerich P, Tappe D, Günther S, Schmidt $\mathrm{S}$, Wolff $\mathrm{D}$, et al. Autochthonous dengue virus infection in Japan imported into Germany, September 2013. Euro Surveill. 2014;19(3):pii=20681. Available from: http://www. eurosurveillance.org/ViewArticle.aspx?Articleld=20681

4. Chao DY, Davis BS, Chang GJ. Development of multiplex real-time reverse transcriptase PCR assays for detecting eight medically important flaviviruses in mosquitoes. J Clin Microbiol. 2007;45(2):584-9. http://dx.doi.org/10.1128/ JCM.00842-06

5. Dick GW, Kitchen SF, Haddow AJ. Zika virus. I. Isolations and serological specificity. Trans R Soc Trop Med Hyg. 1952;46(5):509-20. http://dx.doi. org/10.1016/0035-9203(52)90042-4

6. Haddow AJ, Williams MC, Woodall JP, Simpson DI, Goma LK. Twelve isolations of Zika virus from Aedes (Stegomyia) africanus (Theobald) taken in and above Uganda forest. Bull World Health Organ. 1964;31:57-69.

7. Marchette NJ, Garcia R, Rudnick A. Isolation of Zika virus from Aedes aegypti mosquitoes in Malaysia. Am J Trop Med Hyg. 1969;18(3):411-5.

8. Hayes EB. Zika virus outside Africa. Emerg Infect Dis. 2009;15(9):1347-50. http://dx.doi.org/10.3201/eid1509.090442

9. Foy BD, Kobylinski KC, Chilson Foy JL, Blitvich BJ, Travassos da Rosa A, Haddow AD, et al. Probable non-vector-borne transmission of Zika virus, Colorado, USA. Emerg Infect Dis. 2011;17(5):880-2. http://dx.doi.org/10.3201/eid1705.101939

10. Haddow AD, Schuh AJ, Yasuda CY, Kasper MR, Heang V, Huy R, et al. Genetic characterization of Zika virus strains: geographic expansion of the Asian lineage. PLoS Negl Trop Dis. 2012;6(2):e1477. http://dx.doi.org/10.1371/journal. pntd.0001477

11. Kwong JC, Druce JD, Leder K. Zika virus infection acquired during brief travel to Indonesia. Am J Trop Med Hyg. 2013;89(3):516-7. http://dx.doi.org/10.4269/ajtmh.13-0029

12. Duffy MR, Chen TH, Hancock WT, Powers AM, Kool JL, Lanciotti RS et al. Zika virus outbreak on Yap Island, Federated States of Micronesia. N Engl J Med. 2009;360(24):2536-43. http:// dx.doi.org/10.1056/NEJMoao805715

13. Heang V, Yasuda CY, Sovann L, Haddow AD, Travassos da Rosa AP, Tesh RB, et al. Zika virus infection, Cambodia, 2010. Emerg Infect Dis. 2012;18(2):349-51. http://dx.doi.org/10.3201/ eid1802.111224

14. Lee VJ, Chow A, Zheng X, Carrasco LR, Cook AR, Lye DC, et al. Simple clinical and laboratory predictors of Chikungunya versus dengue infections in adults. PLoS Negl Trop Dis. 2012;6(9):e1786.

15. ProMED-mail. Zika virus - Canada ex Thailand. Archive Number: 20130529.1744108. Available from: http://www.promedmail. org/direct.php?id=1744108

16. ProMED-mail. Zika virus - Japan: ex French Polynesia. Archive Number: 20131219.2126046. Available from: http://www. promedmail.org/direct.php?id $=\mathbf{2 1 2 6 0 4 6}$

17. Kutsuna S, Kato Y, Takasaki T, Moi ML, Kotaki A, Uemura H, Matono T, Fujiya Y, Mawatari M, Takeshita N, Hayakawa K, Kanagawa S, Ohmagari N. Two cases of Zika fever imported from French Polynesia to Japan, December to January 2013. Euro Surveill. 2014;19(4):pii=20683. Available from: http:// www.eurosurveillance.org/ViewArticle.aspx?Articleld $=20683$ 
18. ProMED-mail. Zika virus - French Polynesia (03). Archive Number: 20140123.2227452. Available from: http://www. promedmail.org/direct.php?id=2227452

19. ProMED-mail. Zika virus - New Caledonia. Archive Number: 20140122.2224823. Available from: http://www.promedmail. org/direct.php?id=2224823

20. Lanciotti RS, Kosoy OL, Laven JJ, Velez JO, Lambert AJ, Johnson AJ, et al. Genetic and serologic properties of Zika virus associated with an epidemic, Yap State, Micronesia, 2007. Emerg Infect Dis. 2008;14(8):1232-9. http://dx.doi. org/10.3201/eid1408.080287

21. La Ruche G, Souarès $Y$, Armengaud A, Peloux-Petiot F, Delaunay $P$, Desprès $P$, et al. First two autochthonous dengue virus infections in metropolitan France, September 2010. Euro Surveill. 2010;15(39):pii=119676. Available from: http://www. eurosurveillance.org/ViewArticle.aspx?Articleld=19676

22. Frank C, Höhle M, Stark K, Lawrence J. More reasons to dread rain on vacation? Dengue fever in 42 German and United Kingdom Madeira tourists during autumn 2012. Euro Surveill. 2013;18(14): pii=20446. Available from: http://www. eurosurveillance.org/ViewArticle.aspx?Articleld=20446 